\title{
Influence of physical strain at high altitude on the quality of cardiopulmonary resuscitation
}

\author{
Alexander Egger ${ }^{1,2}$, Maximilian Niederer ${ }^{1,3}$, Katharina Tscherny ${ }^{3}$, Josef Burger ${ }^{1,4}$, Verena Fuhrmann $^{3}$, \\ Calvin Kienbacher ${ }^{3}$, Dominik Roth ${ }^{3^{*}}$ (D) Wolfgang Schreiber ${ }^{3}$ and Harald Herkner ${ }^{3}$
}

\begin{abstract}
Background: High quality cardiopulmonary resuscitation is a key factor in survival with good overall quality of life after out-of-hospital cardiac arrest. Current evidence is predominantly based on studies conducted at low altitude, and do not take into account the special circumstances of alpine rescue missions. We therefore aimed to investigate the influence of physical strain at high altitude on the quality of cardiopulmonary resuscitation.

Methods: Alpine field study. Twenty experienced mountaineers of the Austrian Mountain Rescue Service trained in Basic Life Support (BLS) performed BLS on a manikin in groups of two for $16 \mathrm{~min}$. The scenario was executed at baseline altitude and immediately after a quick ascent over an altitude difference of $1200 \mathrm{~m}$ at $3454 \mathrm{~m}$ above sea level. The sequence of scenarios was randomised for a cross over analysis.

Quality of CPR and exhaustion of participants (vital signs, Borg-Scale, Nine hole peg test) were measured and compared between high altitude and baseline using random-effects linear regression models.

Results: The primary outcome of chest compression depth significantly decreased at high altitude compared to baseline by $1 \mathrm{~cm}(95 \% \mathrm{Cl} 0.5$ to $1.3 \mathrm{~cm}, p<0.01)$. There was a significant reduction in the proportion of chest compressions in the target depth (at least $5 \mathrm{~cm}$ pressure depth) by $55 \%(95 \% \mathrm{Cl} 29$ to $82 \%, p<0.01)$ and in the duration of the release phase by $75 \mathrm{~ms}$ ( $95 \% \mathrm{Cl} 48$ to $101 \mathrm{~ms}, \mathrm{p}<0.01$ ). No significant difference was found regarding hands-off times, compression frequency or exhaustion.

Conclusion: Physical strain during a realistic alpine rescue mission scenario at high altitude led to a significant reduction in quality of resuscitation. Resuscitation guidelines developed at sea level are not directly applicable in the mountain terrain.
\end{abstract}

Keywords: Cardiopulmonary resuscitation (CPR), Manikin, Mountain medicine, Out- of-hospital CPR

\section{Background}

High quality cardiopulmonary resuscitation (CPR) is a key factor in survival with good overall quality of life after out-of-hospital cardiac arrest. Recent guidelines on resuscitation put an increasing level of emphasis on high

\footnotetext{
* Correspondence: dominik.roth@meduniwien.ac.at

${ }^{3}$ Department of Emergency Medicine, Medical University of Vienna, Spitalgasse 23, 1090 Wien, Austria

Full list of author information is available at the end of the article
}

quality chest compressions. Only adequate chest compressions assure sufficient cerebral blood flow, and allow for good neurologic outcome [1].

Current evidence, especially on rate and frequency of chest compressions, target depth, and rate of change between those performing chest compressions is predominantly based on studies conducted at low altitude $(<$ $1000 \mathrm{~m}$ above sea level) ( [2-4]. McDonald et al. (2013) [5] investigated the proportion of correctly performed

(c) The Author(s). 2020 Open Access This article is licensed under a Creative Commons Attribution 4.0 International License, which permits use, sharing, adaptation, distribution and reproduction in any medium or format, as long as you give appropriate credit to the original author(s) and the source, provide a link to the Creative Commons licence, and indicate if changes were made. The images or other third party material in this article are included in the article's Creative Commons licence, unless indicated otherwise in a credit line to the material. If material is not included in the article's Creative Commons licence and your intended use is not permitted by statutory regulation or exceeds the permitted use, you will need to obtain permission directly from the copyright holder. To view a copy of this licence, visit http://creativecommons.org/licenses/by/4.0/ The Creative Commons Public Domain Dedication waiver (http://creativecommons.org/publicdomain/zero/1.0/) applies to the data made available in this article, unless otherwise stated in a credit line to the data. 
chest compressions in an urban environment. These correctly performed chest compressions decreased from $52 \%$ after one minute to $39 \%$ after five minutes. The authors therefore recommended a change of helpers at least every two minutes. This was subsequently included in the ERC-guidelines of 2015 [1].

Recent years have shown a soaring development of mountain tourism, including a large share of elderly tourists and those with increased cardiovascular risk [6]. Mountain rescue services face increasing numbers of non-traumatic cardiac arrest calls $[7,8]$. Although helicopter emergency medical service (HEMS) is widely established in the mountain terrain of developed countries, its use is not always possible due to visibility or weather conditions. This means that rescuers must often perform a fast, straining ascent to the patient, and then perform CPR on scene. As patients often deteriorate only during the helpers' ascent, and exact time of cardiac arrest is not known, CPR usually cannot be withheld due to futility.

To date only few studies have addressed the issue of high-altitude exposure, leading to hypobaric hypoxia, and especially physical strain in these conditions, on quality of CPR.

Wang et al. [9] found a significant deterioration of quality of chest compressions at high altitude $(3100 \mathrm{~m})$. Participants were however flown to the mountain before performing CPR. Hence, physical strain before CPR was not studied, and the study does not reflect the situation of a wearisome ascent prior to resuscitation, often encountered as outlined above.

Narahara et al. [10] evaluated physiological response to CPR at high altitude $(3700 \mathrm{~m})$, and found significantly greater physical effort compared to the strain at sea level. They did, however, not measure the quality of CPR. In addition, rescuers were untrained office workers without any mountaineering experience, rested for 30 min after ascent and before beginning CPR, and performed chest compressions for only five minutes. This might not reflect real practice.

The aim of this work was to investigate the effects of physical strain on quality of cardiopulmonary resuscitation in a realistic high-altitude alpine rescue scenario.

\section{Methods}

This was a randomised cross-over experiment (A-B-A sequence design) [11] in an alpine environment in Austria. The study was approved by the institutional review board of the Medical University of Vienna.

\section{Study subjects}

A total of 20 mountain-experienced members of the Austrian Mountain Rescue Service with regular training in Basic Life Support (BLS) according to ERC guidelines at least 18 years of age were included.

\section{Study setting}

The study was performed at low altitude (Lienz, East Tyrol, Austria, $673 \mathrm{~m}$ above sea level), and after a quick ascent from a mid-height base camp over $1213 \mathrm{~m}$ to a mountain shelter at $3454 \mathrm{~m}$ (Erzherzog Johann Hütte, Großglockner mountain).

\section{Intervention and measurement}

After informed consent, subjects completed a standardized fitness questionnaire (FFB mot) [12]. The FFB is a validated test for overall fitness and divided into a total of 4 subgroups of 7 items each (strength, endurance, agility and coordination). Immediately before CPR, subjects performed testing using the modified nine-hole peg test (NHPT) [13]. This test of dexterity has already been used before as a measure of exhaustion after performing CPR [14-17]. Vital signs (HR, blood pressure, and SpO2) were measured as well.

Participants now performed BLS (CPR 30:2 with bag mask ventilation) on a manikin (Resusci Anne, Laerdal, Norway) for $16 \mathrm{~min}$ in groups of two, switching roles every two minutes. During CPR, quality of CPR (compression depth, frequency of compressions, portion of compression in the target area (at least $5 \mathrm{~cm}$ pressure depth), absolute distance of compressions $(=$ pressure $\mathrm{x}$ frequency), hands-off times, duration of the release phase, and the percentage of time, in which chest compressions were performed) were continuously measured using a feedback device (M-Series, ZOLL-Chelmsford, MA). Subjects' heart rate was also continuously measured during CPR using a chest strap (H7, Vantage V, Polar Electro Oy, Finland). Every two minutes, subjects were asked about their subjective exercise intensity, measured using the BORG-CR 10 [18].

After the scenario, vital signs and NHPT were measured again.

On the next day, participants performed a quick ascent from base camp to the mountain shelter using all their mission equipment and backpack, as they would in a real situation. Immediately after arrival at the mountain shelter, NHPT and vital signs were measured, and participants performed CPR. All measurements took place exactly as at baseline.

After return to baseline height at Lienz on a moderate pace and a resting period of one hour, participants performed CPR for a third time, again exactly as done before, including all measurements.

During all three scenarios, group assignment remained the same. 


\section{Analysis}

Sample size calculations were based on the primary outcome mean relative compression depth. In order to detect a difference of $5 \mathrm{~mm}$ with a standard deviation (SD) of $3.5 \mathrm{~mm}$ at a significance level of $5 \%$ at a power of $90 \%$, a total of 16 subjects were needed. To allow for the study design, we decided to include a total of 20 participants in ten teams.

Continuous data are presented as mean \pm standard deviation, count data are presented as absolute number and relative frequency. All outcome variables were compared between the "high altitude" and "baseline altitude" measurement. The assignment of the analysis to use baseline altitude data from before (i.e. "baseline altitude - high altitude" sequence) or after (i.e. "high altitude baseline altitude" sequence) the high-altitude measurement was randomly chosen to take into account any potential learning effects. The remainder baseline measurements were discarded, which results in a randomised cross-over experiment.

The differences between high altitude and baseline and their 95\% confidence intervals were calculated using linear random effects models to allow for the study design with 'team' as the unit of analysis and altitude as the covariable for each outcome separately. The null hypothesis of no difference between the altitudes was formally tested using the Wald test from the above models. We tested for an interaction of the differences with ascension speed. We performed sensitivity analyses to investigate properly randomised group allocation by comparing before-after with after-before effects. We also used the individual level analysis as a sensitivity analysis, knowing that hands-off time is more reliable at the team-level, and team-level analysis better reflects patient care. For data management and analysis, we used MS Excel and Stata (StataCorp, College Station, TX). A twosided $p$ value less 0.05 was generally considered significant.

\section{Results}

\section{Characteristics of study subjects}

A total of 20 subjects (three, 15\% female) were included in the study. Body mass index (BMI) and FFB Mot showed high fitness levels (see Table 1 for baseline information). All subjects were able to complete the scenarios as planned.

\section{Main results}

The primary outcome "mean depth of chest compression" decreased significantly at high altitude compared to baseline by $1.0 \mathrm{~cm}(95 \% \mathrm{CI} 0.5$ to $1.3, p<0.01)$ (See Fig. 1).

There was also a significant reduction in the percentage of compressions in the target area (at least $5 \mathrm{~cm}$
Table 1 Demographics of study subjects

\begin{tabular}{ll}
\hline & Total $(\boldsymbol{n}=20)$ \\
\hline Age (years) (mean, SD) & $38(12)$ \\
Height (cm) (mean, SD) & $178(6)$ \\
Weight (kg) (mean, SD) & $74(8)$ \\
BMI (kg/m²) (mean, SD) & $23(2)$ \\
Smoker (\%) & $2(10 \%)$ \\
FFB Mot (mean, SD), max. 5 & \\
Strength & $5(0)$ \\
$\quad$ Endurance & $5(1)$ \\
$\quad$ Agility & $5(0)$ \\
Coordination & $5(0)$ \\
$\quad$ Backpack weight (kg) (median, IQR) & $10(3)$ \\
Ascent time (minutes) (min to max, mean, SD) & 104 to 246, 178 (40) \\
\hline BMl Body mass index &
\end{tabular}

pressure depth) by 55\% (95\% CI 29 to $82 \%, p<0.01$ ) from $72 \%$ of all compressions to only $17 \%$, and in the duration of the release phase by $75 \mathrm{~ms}$ ( $95 \%$ CI 48 to $101 \mathrm{~ms}, \mathrm{p}<0.01$ ).

There was no significant difference in hands-off times, compression frequency, and proportion of time performing chest compressions. See Table 2 for details.

Regarding vital signs, range of heart rate increased at high altitude compared to baseline (126 before to 121 bpm after vs. 74 before to $84 \mathrm{bpm}$ after CPR), and $\mathrm{SpO} 2$ decreased at higher altitude ( 87 to $88 \%$ vs. 97 to $98 \%$ ). BORG scale as a subjective measure of exhaustion after 2 min of CPR was significantly higher at high altitude than at baseline (2.4 vs. 1.8); however this difference disappeared at the end of CPR (2.6 vs. 2.7). No differences were found in the NHPT as an objective measure of exhaustion between altitudes, neither before nor after CPR. See Table 3 for details.

There was no interaction of ascension speed with the main effects. Sensitivity analysis showed no differences in per-group as compared to per-individual analysis. We also found no differences between those randomised to baseline-before as compared to those baseline-after, indicating successful randomisation and rejecting a learning effect as alternative explanation for the main effect.

\section{Discussion}

Performing high-quality CPR requires a high level of physical effort even at sea level [5].

In a group of trained and experienced subjects, the physical strain of a realistic alpine rescue scenario at high altitude resulted in a significant reduction in quality of CPR.

To our knowledge this was the first study on the influence of physical strain at high altitude on quality of 


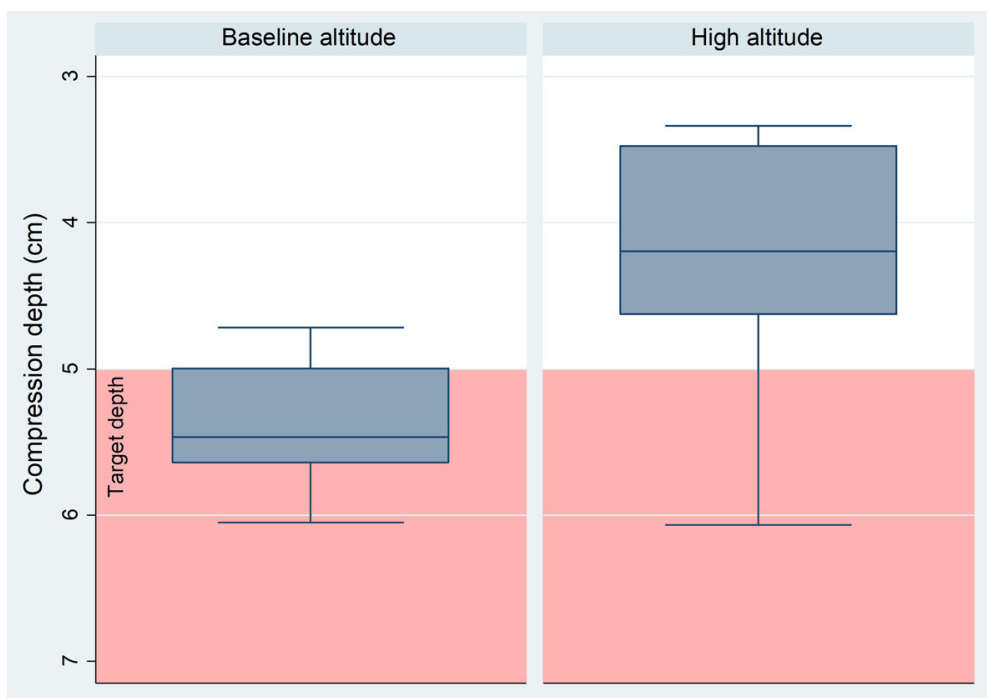

Fig. 1 Mean compression depth at baseline and high altitude

CPR. Our findings however complement previous studies, in which high-altitude CPR (without prior physical strain) was investigated. Wang and colleagues reported a mean compression depth of $4.9 \mathrm{~cm}$ at $3100 \mathrm{~m}$ as compared to $5.3 \mathrm{~cm}$ at sea level. This difference of $0.4 \mathrm{~cm}$ was distinctly less pronounced than our findings of a reduction of $1.0 \mathrm{~cm}$. We believe this may be explained by the different scenario used in the study by Wang: Subjects were flown to the mountain and performed $5 \mathrm{~min}$ of chest compression-only CPR vs. a quick ascent from base camp to the mountain shelter, and $16 \mathrm{~min}$ of 30:2 CPR in groups of two [9]. Although this represents one common scenario, use of HEMS might often not be possible due to weather or daytime restrictions, as outlined before.

We found no difference in compression frequency, hands-off time, and proportion of time performing chest compressions. No previous data exists on the latter two, but regarding compression frequency, our findings are consistent with those of Wang et al. [9].

Our participants were members of the mountain rescue service with excellent physical fitness. This was reflected by only the slightest change of heart rate after performing CPR, both at low and high altitudes, and the low degree of physical exhaustion, both subjective (as measured by the BORG scale), and objective (as measured by the NHPT).

Although participants reported slightly higher BORG scales after 2 min of CPR at high altitude compared to low altitude, this difference disappeared over the full duration of $16 \mathrm{~min}$. These findings are again distinctly different to previous reports. Wang et al., who studied health care professionals, who were however not professional mountaineers, found a severe increase in heart rate ( 81 before, 103 after CPR at sea level; 94 before, 115 after at high altitude, compared to 74 before and 84 after, and 126 before and 121 after in our study), as well as in BORG scale (6.7 at beginning, 13.8 at end on sea level; 9.6 at beginning, 14.4 at end on high altitude; 1.8, 2.7 and 2.4 and 2.6 in our study) [9]. Narahara reported similar findings in laymen, with BORG scales of 13 after CPR at sea level and 15 after $\mathrm{CPR}$ at 3700 [10]. Interestingly, despite these large discrepancies in physical exhaustion between professional mountain rescue personnel and other rescuers, the degree of hypoxemia in our participants $(\mathrm{SpO} 288 \%$ at high altitude) was very similar to those in the studies of Wang $(88 \%)$ and Narahara ( $88 \%$ at $2500 \mathrm{~m} ; 80 \%$ at $3700 \mathrm{~m}$ ).

Notably, despite the low degree of physical exhaustion reported by participants, quality of CPR was significantly

Table 2 Main results

\begin{tabular}{|c|c|c|c|c|}
\hline & Baseline & High altitude & Difference (with 95\% Cl) & $p$-value \\
\hline Compression depth (cm, mean, SD) & $5.4(1.6)$ & $4.3(0.9)$ & $-1.0(-1.3$ to -0.5$)$ & $<0.001$ \\
\hline Compression frequency (pm, mean, SD) & $120(37)$ & $123(11)$ & $3(-4$ to 10$)$ & 0.36 \\
\hline Compressions in target depth $(\%$, mean, SD) & $72(31)$ & $17(34)$ & $-55(-82$ to -29$)$ & $<0.001$ \\
\hline Hands-off time (s, mean, SD) & $201(63)$ & $189(20)$ & $-13(-27$ to 2$)$ & 0.09 \\
\hline Duration of release phase (ms, mean, SD) & $414(132)$ & $339(82)$ & $-75(-101$ to -48$)$ & $<0.001$ \\
\hline Proportion of time performing chest compressions (\%, mean, SD) & $79(23)$ & $80(2)$ & $1(-6$ to 3$)$ & 0.20 \\
\hline
\end{tabular}


Table 3 Vital signs and measures of physical strain of study subjects. All values are mean (SD)

\begin{tabular}{lcl}
\hline & Baseline & High Altitude \\
\hline Systolic blood pressure $(\mathbf{m m H g})$ & $136(14)$ \\
Pre-CPR & $134(10)$ & $129(9)$ \\
Post-CPR & $139(13)$ & \\
Diastolic blood pressure $(\mathbf{m m H g})$ & $83(9)$ \\
Pre-CPR & $78(10)$ & $81(8)$ \\
Post-CPR & $81(11)$ & \\
Heart rate (beats/min) & & $126(13)$ \\
Pre-CPR & $74(17)$ & $121(18)$ \\
Post-CPR & $84(16)$ & $87(3)$ \\
SpO2 (\%) & & $88(4)$ \\
Pre-CPR & $97(2)$ & \\
Post-CPR & $98(1)$ & $2.4(0.8)$ \\
BORG - Scale & & $2.6(0.8)$ \\
After 2 min & $1.8(1.0)$ & $26(5)$ \\
End of CPR & $2.7(1.1)$ & $27(6)$ \\
NHPT (sec.) & & \\
Pre-CPR & $24(4)$ & \\
Post-CPR & $24(4)$ & \\
\hline NHPT nine hole & &
\end{tabular}

NHPT nine hole peg test

worse at high altitude. This suggests that professional mountain rescue personnel were not able to judge the quality of their CPR at high altitude.

Our findings have severe implications on the performance of CPR in mountain terrain. Although the 2015 ERC guidelines for the first time encompassed distinct chapters on specific mountain emergencies, such as avalanches or hypothermia, the universal CPR algorithm (for non-hypothermic patients) still remains the same. This algorithm is based on findings from studies on low altitude and cannot be directly transferred to the environment of mountain rescue service.

We found that CPR performed by physically fit and highly trained professionals according to current BLS guidelines at high altitude led to a proportion of sufficient chest compressions of only $17 \%$. This may seriously impair patient outcome. Future research should therefore focus specifically on different strategies to optimise quality of chest compressions at high altitude. These strategies could include more frequent change of roles (which, on the other hand, could increase handsoff times), use of mechanical CPR devices and feedbackdevices (which, however, is limited by the weight rescuers could carry).

\section{Conclusion}

Physical strain during a realistic alpine rescue mission scenario at high altitude led to a significant reduction in quality of resuscitation. Resuscitation guidelines developed at sea level are not directly applicable in the mountain terrain.

\section{Abbreviations}

95\% Cl: 95\% confidence interval; BLS: Basic Life Support; BMI: Body mass index; CPR: Cardiopulmonary resuscitation; FFB: Fitness questionnaire; HEMS: Helicopter emergency medical service; HR: Heart rate; NHPT: Modified nine-hole peg test; SD: Standard deviation; SpO2: Oxygen saturation

\section{Acknowledgements}

We are indebted to the members of the Austrian Mountain Rescue Service and the Austrian Army (High Mountain Infantry Battalion 24) for their support in the conduct of this study.

Conflict of interest

None.

\section{Authors' contributions}

AE participated in literature search, study design, data collection, data analysis, data interpretation and writing. DR participated in study design, data analysis. MN and KT and CK participated in study design, critical revision and writing. WS and $\mathrm{HH}$ and JB and VF participated in literature search, study design, data collection and critical revision. All authors read and approved the final manuscript.

\section{Funding}

There was no external funding of the study.

Availability of data and materials

The datasets used and/or analysed during the current study are available from the corresponding author on reasonable request.

\section{Ethics approval and consent to participate}

The study was approved by the ethics committee of the Medical University of Vienna (\#1291). All participants provided written informed consent to participate.

\section{Consent for publication}

Not applicable.

\section{Competing interests}

The authors declare that they have no competing interests.

\section{Author details}

${ }^{1}$ Mountain Rescue Service Austria, Schelleingasse 26/2/2, 1040 Wien, Austria. ${ }^{2}$ Department of Anaesthesiology and Intensive Care Medicine, Hospital Scheibbs, Eisenwurzenstraße 26, 3270 Scheibbs, Austria. ${ }^{3}$ Department of Emergency Medicine, Medical University of Vienna, Spitalgasse 23, 1090 Wien, Austria. ${ }^{4}$ Department of Paediatrics, Hospital Lienz, Emanuel von Hibler-Straße 5 A, 9900 Lienz, Austria.

Received: 28 January 2020 Accepted: 2 March 2020

Published online: 06 March 2020

\section{References}

1. Perkins GD, Handley AJ, Koster RW, Castren M, Smyth MA, Olasveengen T, et al. European resuscitation council guidelines for resuscitation 2015: section 2. Adult basic life support and automated external defibrillation. Resuscitation. 2015;95:81-99.

2. Idris AH, Guffey D, Aufderheide TP, Brown S, Morrison $\amalg$, Nichols P, et al. Relationship between chest compression rates and outcomes from cardiac arrest. Circulation. 2012;125(24):3004-12.

3. Idris AH, Guffey D, Pepe PE, Brown SP, Brooks SC, Callaway CW, et al. Chest compression rates and survival following out-of-hospital cardiac arrest. Crit Care Med. 2015:43(4):840-8.

4. Stiell IG, Brown SP, Nichol G, Cheskes S, Vaillancourt C, Callaway CW, et al. What is the optimal chest compression depth during out-of-hospital cardiac arrest resuscitation of adult patients? Circulation. 2014;130(22):1962-70. 
5. McDonald $\mathrm{CH}$, Heggie J, Jones $\mathrm{CM}$, Thorne $\mathrm{CJ}$, Hulme J. Rescuer fatigue under the 2010 ERC guidelines, and its effect on cardiopulmonary resuscitation (CPR) performance. Emerg Med J. 2013;30(8):623-7.

6. Martinez-Caballero CM, Sierra QE. Epidemiology of cardiac events during Prehospital Care in Mountain Rescues Conducted in Aragon. Wilderness Environ Med. 2019;30(1):22-7.

7. Jung E, Park JH, Kong SY, Hong KJ, Ro YS, Song KI, et al. Cardiac arrest while exercising on mountains in national or provincial parks: a national observational study from 2012 to 2015. Am J Emerg Med. 2018;36(8):13505.

8. Strohle M, Vogele A, Neuhauser P, Rauch S, Brugger H, Paal P. Sudden cardiac arrest and cardiopulmonary resuscitation with automated external defibrillator in the Austrian Mountains: a retrospective study. High Alt Med Biol. 2019;20(4):392-8.

9. Wang JC, Tsai SH, Chen YL, Hsu CW, Lai KC, Liao WI, et al. The physiological effects and quality of chest compressions during CPR at sea level and high altitude. Am J Emerg Med. 2014;32(10):1183-8.

10. Narahara H, Kimura M, Suto T, Saito H, Tobe M, Aso C, et al. Effects of cardiopulmonary resuscitation at high altitudes on the physical condition of untrained and unacclimatized rescuers. Wilderness Environ Med. 2012;23(2): $161-4$.

11. Senn S. Cross-over trials in clinical research. Chichester: John Wiley; 1993.

12. Bös K, Abel T, Woll A, Niemann S, Tittlbach S, Schott N. Der Fragebogen zur Erfassung des motorischen Funktionsstatus (FFB-Mot). Diagnostica. 2002; 48(2):101-11.

13. Mathiowetz V, Weber K, Kashman N, Volland G. Adult norms for the nine hole peg test of finger dexterity. Occup Ther J Res. 1985;5(1):24-38.

14. Herkner H, Eisenburger P, Havel C, Laggner AN. Dashing with scooters to inhospital emergencies: a randomised cross-over experiment. Resuscitation. 2002;52(3):293-6.

15. Havel C, Herkner H, Haugk M, Richling N, Riedmuller E, Trimmel H, et al. Physical strain on advanced life support providers in different out of hospital environments. Resuscitation. 2008:77(1):81-6.

16. van Tulder R, Roth D, Krammel M, Laggner R, Heidinger B, Kienbacher $C$, et al. Effects of repetitive or intensified instructions in telephone assisted bystander cardiopulmonary resuscitation: an investigator-blinded, 4-armed, randomized, factorial simulation trial. Resuscitation. 2014:85(1):112-8

17. Fischer H, Zapletal B, Neuhold S, Rutzler K, Fleck T, Frantal S, et al. Single rescuer exertion using a mechanical resuscitation device: a randomized controlled simulation study. Acad Emerg Med. 2012;19(11):1242-7.

18. Borg E, Borg G. A demonstration of level-anchored ratio scaling for prediction of grip strength. Appl Ergon. 2013;44(5):835-40.

\section{Publisher's Note}

Springer Nature remains neutral with regard to jurisdictional claims in published maps and institutional affiliations.

Ready to submit your research? Choose BMC and benefit from:

- fast, convenient online submission

- thorough peer review by experienced researchers in your field

- rapid publication on acceptance

- support for research data, including large and complex data types

- gold Open Access which fosters wider collaboration and increased citations

- maximum visibility for your research: over $100 \mathrm{M}$ website views per year

At $\mathrm{BMC}$, research is always in progress.

Learn more biomedcentral.com/submissions 